\title{
Chronic cough in the Holmes-Adie syndrome: association in five cases with autonomic dysfunction
}

\author{
J Kimber, D Mitchell, C J Mathias
}

Neurovascular

Medicine Unit,

Division of

Neuroscience and

Psychological

Medicine, Imperial

College School of

Medicine, and

Autonomic Unit, University

Department of Clinical

Neurology, National

Hospital for Neurology

and Neurosurgery,

Queen Square,

Institute of Neurology,

University College

London, UK

$\mathrm{J}$ Kimber

C J Mathias

Chest and Allergy

Unit, Department of

Medicine, St Mary's

Hospital, London

D Mitchell

Correspondence to: Dr J Kimber, Neurovascular Medicine Unit, Division of Neuroscience and Psychological Medicine, Imperial College School Of Medicine, St Mary's

Hospital, Clarence Wing, Praed Street, London W2 1NY, UK. Telephone 0044 171886 1468; fax 0171886 1540 .

Received 23 September 1997 and in final revised form 4 March 1998

Accepted 9 March 1998

\begin{abstract}
The Holmes-Adie syndrome consists of unilateral or bilateral tonic pupils with near light dissociation and tendon areflexia. It is associated with autonomic disturbances affecting sudomotor and vasomotor function. Five such patients are reported on who also had a troublesome chronic dry cough, which was of unknown aetiology and was resistant to a range of treatments. The cough may be related to involvement of afferent or efferent pathways in the vagus. Chronic cough may be an accompaniment in the HolmesAdie syndrome, like other forms of autonomic dysfunction.

(F Neurol Neurosurg Psychiatry 1998;65:583-586)
\end{abstract}

Keywords: Holmes-Adie syndrome; autonomic dysfunction; cough

The Holmes-Adie syndrome ${ }^{12}$ (tonic pupil, near-light dissociation, and tendon areflexia) has been associated with a range of autonomic disturbance that includes orthostatic hypotension, ${ }^{3}$ impairment of cardiovascular reflexes, ${ }^{45}$ segmental $^{6}$ and generalised hypohydrosis (Ross's syndrome), ${ }^{7}$ carotid gustatory syndrome, ${ }^{8}$ and chronic diarrhoea. ${ }^{9}$ Limited histological studies in this condition indicate loss of ganglion cells in the parasympathetic ciliary ganglia $^{10}$ which correlates with the pupillary abnormalities. Degeneration of the dorsal root ganglia or the fasciculus gracilis and cuneatus may explain the absent tendon reflexes. ${ }^{11}$ Autonomic dysfunction has been variously ascribed to lesions of both afferent and efferent sympathetic and parasympathetic neurones.

Although Holmes-Adie syndrome is considered to be benign and of unknown aetiology, troublesome symptoms may result from autonomic dysfunction; these include hyperhydrosis, heat intolerance, and syncope. We report a further feature in five patients with HolmesAdie syndrome in whom there was a persistent dry cough, of unknown aetiology.

\section{Methods and results}

The patients are described individually. None had a history of exposure to irritant chemicals or impairment of exercise tolerance. All had bouts of paroxysmal dry coughing during the day, with lesser frequency at night. Cough was not provoked by lying flat. None was taking angiotensin converting enzyme inhibitors, and all underwent detailed cardiovascular autonomic function tests with thermoregulatory sweat testing ${ }^{12}$ (table 1). Pulmonary function testing and other investigations to determine possible causes for their cough are shown in table 2 . In all the chest radiograph was normal. Thorax CT was questionably abnormal in patient 4, with peribronchial shadowing in the right upper zone that may have represented localised bronchiectasis, but bronchoscopy was normal. There were no features of gastrooesophageal reflux and all were treated with $\mathrm{H}_{2}$ antagonists with no benefit. In the three who underwent cine-video fluoroscopy, there was no evidence of laryngeal aspiration. In three, capsaicin challenge indicated increased cough sensitivity. Laboratory testing to exclude secondary causes of autonomic dysfunction included glucose, erythrocyte sedimentation rate, serum electrophoresis, autoantibody screen, treponemal serology, and brain MRI, and the results were normal in each case. Where Holmes-Adie syndrome was not previously documented, patients also underwent pupillography and EMG (to show absent or reduced $\mathrm{H}$ waves) to confirm further the diagnosis.

\section{Case reports}

Patient 1 was a 39 year old white man, a nonsmoker, who had been investigated when aged 21 for anisocoria and a tonic right pupil that was unresponsive to light. When aged 35 he developed hyperhydrosis affecting the right arm and trunk; a right cervical sympathectomy was performed with only minimal improvement. He then developed symptoms of postural hypotension and was bothered by frequent paroxysms of coughing that resulted in syncope on several occasions. There was no history of lung disease.

Examination indicated a dilated right pupil with near-light dissociation. Other cranial nerves were normal. Tendon reflexes were absent bilaterally. Sweating was marked in the right axilla. There were no respiratory system 
Table 1 Details of investigations of the respiratory and allied systems to determine the cause of cough

\begin{tabular}{|c|c|c|c|c|c|}
\hline & Patient 1 & Patient 2 & Patient 3 & Patient 4 & Patient 5 \\
\hline Chest $x$ ray film & Normal & Normal & Normal & Normal & Normal \\
\hline CT thorax & Normal & - & - & $\begin{array}{l}\text { Peribronchial shadowing } \mathrm{R} \\
\text { upper zone }\end{array}$ & - \\
\hline \multicolumn{6}{|c|}{ Spirometry (observed/expected (n (\%))) } \\
\hline Vital capacity (1) & $5.4(104)$ & $1.9(89)$ & $2.4(114)$ & $2.9(104)$ & $2.8(117)$ \\
\hline $\mathrm{FEV}_{1}(\mathrm{l})$ & $4.5(110)$ & $1.6(90)$ & $1.8(126)$ & $2.4(109)$ & $2.0(99)$ \\
\hline FEV/VC (\%) & $83(108)$ & $84(91)$ & $73(112)$ & $83(98)$ & $71(91)$ \\
\hline $\begin{array}{l}\text { Peak expiratory flow } \\
\text { rate }(1 / \mathrm{min})\end{array}$ & $710(114)$ & $450(90)$ & $315(106)$ & $475(117)$ & $147(50)$ \\
\hline $\begin{array}{l}\text { Transfer factor }\left(\mathrm{T}_{\mathrm{L}} \mathrm{CO}\right) \\
(\mathrm{ml} / \mathrm{min} / \mathrm{mm} \mathrm{Hg})\end{array}$ & $26(74)$ & - & $6.3(105)$ & $25(109)$ & $15.1(72)$ \\
\hline Bronchoscopy & Normal & - & - & Normal & - \\
\hline Nasolaryngoscopy & $\begin{array}{l}\text { Small pharyngeal pouch "not functionally } \\
\text { significant" }\end{array}$ & Normal & Normal & Mild rhinitis & Normal \\
\hline Cine-video fluoroscopy & $\begin{array}{l}\text { Minimal pooling in valleculae and pyriform fossae. } \\
\text { Reduced tongue base contractions }\end{array}$ & $\begin{array}{l}\text { Minimal reduction in } \\
\text { tongue base motility }\end{array}$ & - & $\begin{array}{l}\text { Mild reduction in tongue } \\
\text { base contractions }\end{array}$ & - \\
\hline OGD & Small hiatus hernia & Small hiatus hernia & - & Normal & Normal \\
\hline Capsaicin challenge & Increased sensitivity & Increased sensitivity & - & Increased sensitivity & - \\
\hline
\end{tabular}

$\mathrm{OGD}=$ oesophagogastroduodenoscopy $\mathrm{FEV}_{1}=$ forced expiratory flow in 1 minute; —=not performed; $\mathrm{T}_{\mathrm{L}} \mathrm{CO}=$ transfer coefficient for carbon monoxide.

abnormalities. Cardiovascular autonomic testing suggested an afferent baroreceptor lesion. Paroxysmal coughing during head up tilt resulted in a fall in blood pressure from 151/99 to $98 / 70 \mathrm{~mm} \mathrm{Hg}$, inducing presyncope. He was treated with a high salt intake and fludrocortisone to improve orthostatic tolerance. Probanthine (15 mg thrice daily) and clonidine (25 mg thrice daily) were used to reduce hyperhydrosis but were stopped due to a dry mouth. Investigation of cough (table 1) indicated no identifiable aetiology. The cough was refractory to therapeutic trials of inhaled, nasal, and oral steroids, lignocaine spray and nebuliser, local anaesthetic lozenges, and oral $\mathrm{H}_{2}$ antagonists. The patient is currently on proprietary antitussive agents (containing morphine, capsiacin, and ipecachuana).

Patient 2 was a 58 year old white woman, who had stopped smoking 15 years previously. When 51 , she noticed inequality of pupils. Two years later she developed asymmetric facial sweating and paroxysmal coughing attacks, particularly while eating and during prolonged talking. She had occasional dyspnoea but no wheezing and on investigation was diagnosed as having late onset asthma. Although bronchodilator treatment improved the dyspnoea it did not prevent coughing. She had been hypertensive and noted that treatment with an angiotensin converting enzyme inhibitor exacerbated her cough and the drug was withdrawn. Examination confirmed a left tonic pupil with near light dissociation, hemifacial anhydrosis, and tendon areflexia. Cardiovascular and respiratory examination was unremarkable. Cardiovascular autonomic testing showed minor abnormalities. Investigations for cough indicated mild reversible airway obstruction. Treatment with inhaled bronchodilators and steroids (salbutamol, salmeterol, beclomethasone) produced a partial reduction in coughing. Oral $\mathrm{H}_{1}$ (loratadine) and $\mathrm{H}_{2}$ antagonists (ranitidine) and nasal steroids (fluticasone and beclomethasone drops) produced no further benefit. The patient noted that coughing, especially during public speaking, was markedly reduced after taking lomotil (diphenoxylate hydrochloride and atropine sulphate); inhaled ipratropium bromide ( $40 \mu \mathrm{g}$ four times a day) has been initiated with moderate benefit.

Patient 3 was a 59 year old white woman, a non-smoker with a 20 year history of postural dizziness. Previous investigation at the age of 40 had documented bilateral tonic pupils in association with tendon areflexia. Subsequently she developed facial anhydrosis and a chronic dry cough. Examination confirmed small irregular pupils with near light dissociation and tendon areflexia with no other CNS abnormality. Cardiovascular and respiratory systems were unremarkable. Cardiovascular autonomic testing indicated baroreceptor dysfunction (orthostatic hypotension, blocked blood pressure response to Valsalva's manoeuvre, and exaggerated pressor responses). Investigations for cough identified no obvious aetiology. Treatment with proprietary antitussive drugs resulted in some improvement of symptoms.

Patient 4 was a 31 year old woman, a non-smoker of mixed (white-AfroCaribbean) origin. On presentation at the age of 26 she had a 2 year history of posture induced syncope together with paroxysmal throbbing headaches and epistaxis provoked by prolonged recumbency. She had had mild asthma since childhood and used a salbutamol inhaler intermittently. Examination indicated a right tonic pupil with near light dissociation. Tendon reflexes in the lower limbs were reduced. There were no other neurological abnormalities. Cardiovascular and respiratory examination was normal. Cardiovascular autonomic testing confirmed orthostatic hypotension and pressor stimuli raised blood pressure at times to 250/120 mm Hg suggesting impaired baroreceptor afferent activity. Methyldopa $(250 \mathrm{mg}$ twice daily) reduced the paroxysmal hypertensive episodes. A prominent symptom was persistent dry coughing that was refractory to increasing bronchodilator treatment and this was investigated further (table 2). Treatment with inhaled and nasal steroids (fluticasone inhaler $(200 \mu \mathrm{g}$ twice daily); fluticasone nasal spray $(50 \mu \mathrm{g} /$ nostril daily)) partially improved her cough. Oral $\mathrm{H}_{1}$ (chlorpheniramine) and $\mathrm{H}_{2}$ antagonists (ranitidine) were of no further benefit. She continued to have an unremitting dry cough. 
Table 2 Details of cardiovascular autonomic function tests in patients

\begin{tabular}{|c|c|c|c|c|c|}
\hline & Patient 1 & Patient 2 & Patient 3 & Patient 4 & Patient 5 \\
\hline Orthostatic hypotension & + & - & + & + & - \\
\hline Pressor responses & Exaggerated & Normal & Exaggerated & Exaggerated & Exaggerated \\
\hline Hyperventilation (expected increase in heart rate: $15-21 \mathrm{bpm}$ ) & $\uparrow \uparrow(+33)^{\star}$ & $\downarrow(+6)$ & $\uparrow \uparrow(+40)^{\star}$ & $\uparrow \uparrow(+45)^{\star}$ & $\downarrow(+2)$ \\
\hline Sinus arrhythmia (expected increase in heart rate: $15-19 \mathrm{bpm}$ ) & 3 & 17 & $<5$ & 10 & $<5$ \\
\hline Valsalva's manoeuvre & & & & & \\
\hline $\mathrm{BP}$ response & Abnormal & Normal & Abnormal & Abnormal & Abnormal \\
\hline Ratio (normal $>1.2$ ) & 1.09 & 1.63 & 1.07 & 1.16 & 1.13 \\
\hline
\end{tabular}

*The increased response may in part have been due to coughing, often induced by hyperventialtion.

$\mathrm{BP}=$ blood pressure; $\mathrm{HR}=$ heart rate; $\mathrm{bpm}=$ beats $/ \mathrm{min}$.

Orthostatic hypotension indicates a postural fall in systolic blood pressure $>20 \mathrm{~mm} \mathrm{Hg}$ on head up tilt.

Patient 5 was a 66 year white woman who was a non-smoker. She had presented 12 years previously with a troublesome dry cough. She had also noticed a unilateral dilated pupil and began having episodic diarrhoea up to 12 times daily. Panendoscopy plus large bowel biopsies failed to identify a cause. She then also noted truncal hyperhydrosis and postural dizziness. She had dry eyes and hypostomia with no history of joint or skin inflammation and no reduction in exercise tolerance. Further serological investigation indicated positive anti-Ro antibodies, suggesting primary Sjögren's syndrome. Examination showed near light dissociation of the right pupil and tendon areflexia. Truncal sweating was prominent bilaterally. There were no other abnormalities. Cardiovascular autonomic function tests indicated no abnormalities and investigation of her cough identified no obvious cause. She had been treated with numerous courses of antibiotics for presumed upper respiratory tract infections and with antirhinitis treatment and cough suppressants containing opiates without effect. Proprietary antitussive agents containing capsaicin are currently being assessed.

\section{Discussion}

Chronic cough is a common symptom and may be caused by various stimuli which range from neoplasms, inflammatory lung disease, and postnasal drip to increased cough sensitivity resulting from respiratory tract infections, asthma, gastro-oesophageal reflux, and drugs such as angiotensin converting enzyme inhibitors. ${ }^{13}$ Despite extensive investigation, a proportion of patients have no diagnostic reason to explain their cough. Our findings suggest that the Holmes-Adie syndrome may be a disorder associated with a chronic dry cough.

All our patients had typical ocular findings and tendon areflexia indicative of Holmes-Adie syndrome. They also had associated autonomic impairment, either cardiovascular or sudomotor, and this combination presumably reflects the interests of the referral units. All were investigated in detail for autonomic dysfunction and also for a cause for their coughing. Coughing was provoked in each patient by deep breathing or hyperventilation during autonomic testing, suggestive of increased cough reflex sensitivity. This was formally tested in three. All were investigated for asthma. One patient had had mild asthma as a child and another was a probable late onset asthmatic; asthma may cause chronic cough and increased cough sensitivity, but there was no relation between coughing and indices of airflow limitation and furthermore the cough did not respond to effective asthma treatment. Treatment with $\mathrm{H}_{2}$ antagonists for occult gastro-oesophageal reflux, and $\mathrm{H}_{1}$ antagonists and topical steroids for rhinitis, were of no benefit.

Consideration of the cough reflex pathways enables speculation on the mechanism of cough in these patients. Afferent pathways carry stimuli from receptors in the trachea, larynx, and larger bronchi to the dorsal medulla via the vagus nerve. The motor (efferent) reflex arc innervates the muscles of the larynx, diaphragm, and chest wall. Efferent pathways for bronchiolar smooth muscle and mucosal glands are also vagal in origin. In Holmes-Adie syndrome, cardiovascular ${ }^{414}$ and tendon reflex abnormalities suggest an impairment of the afferent reflex arc. This alone is an unlikely explanation as in animals with neuropathy induced by acrylamide(affecting vagal myelinated afferent fibres), and in diabetic patients with peripheral autonomic neuropathy, the cough response to mechanical stimulation ${ }^{15}$ and citric acid is diminished. ${ }^{16}$ Whether impaired afferent activity resulted in a relative increase in vagal efferent traffic cannot be discounted.

An increased sensitivity of airway cough receptors is a possible explanation as cough reflex sensitivity using capsaicin challenge was increased in each of the three patients tested. This may have been due to changes in the local environment of sensory nerves in the airway, particularly bradykinin and prostaglandin production $^{17}$ as has been noted in cough induced by angiotensin converting enzyme inhibitor.${ }^{13}$ In the three patients who underwent cine-video fluoroscopic examination of swallowing, there were minor abnormalities of coordination that may have provided an abnormal stimulus for coughing; there was, however, no clear association with swallowing or eating except in patient 2 , and in none was there evidence of laryngeal aspiration.

One patient responded to an oral and later an inhaled anticholinergic agent and the mechanism may have been through reduced vagally stimulated (muscarinic) effects on bronchial secretions. In patients with refractory epilepsy fitted with vagal nerve stimulators, a proportion experienced coughing corresponding to the stimulator "on" period. ${ }^{18} \mathrm{~A}$ therapeutic trial of anticholinergic agents, as in patient 2, may help to determine the vagal efferent component to the cough. 
There is uncertainty about the CNS component of the cough reflex. In Holmes-Adie syndrome there is no known evidence of a clear central abnormality, and although it cannot be discounted or tested this seems less likely.

Although chronic cough is a common symptom, detailed investigation in each of our patients with Holmes-Adie syndrome showed no obvious aetiology for their cough; in four out of five patients the coughing seemed temporally related to the onset of other autonomic features. In Holmes-Adie syndrome the autonomic features affecting cardiovascular and sudomotor function favour a patchy involvement, with resultant exaggerated activity, such as increased pressor responses in some and compensatory hyperhidrosis in others. Whether a similar process affects the autonomic control of the respiratory tract and involves the pathways involved in the cough reflex in such patients can only be speculated on at this stage. However, in all five patients, chronic cough produced appreciable morbidity. We conclude that these findings indicate yet another troublesome symptom, the mechanism of which needs to be further elucidated, to add to abnormalities of the somatic and autonomic nervous system previously described in the Holmes-Adie syndrome.

1 Adie W J. Tonic pupils and absent tendon reflexes. A benign disorder sui generis: its complete and incomplete forms. Brain 1932;55:98-113.

2 Holmes G. Partial iridoplegia associated with symptoms of other diseases of the nervous system. Trans Opthal Soc UK 1931;51:209.
3 Croll W, Duthie R, MacWilliam J. Postural hypotension: a report of a case. Lancet 1935;i:194-198.

4 Bacon P, Smith S. Cardiovascular and sweating function in patients with Holmes-Adie syndrome. $f$ Neurol Neurosurg Psychiatry 1993;56:1096-102.

5 Johnston R, McLellan D, Love D. Orthostatic hypotension and the Holmes-Adie syndrome: a study of two patients with afferent baroreceptor block. I Neurol Neurosurg Psychiatry 1971;34:562-70.

6 Lucy D, Allen M, Van Thompson H. Holmes-Adie syndrome with segmental hypohydrosis. Neurology 1967; 17:763-9.

7 Ross A. Progressive selective sudomotor degeneration. A case with coexisting Adie's syndrome. Neurology 1958;8: $809-17$.

8 Shibaski $\mathrm{H}$, Tomi $\mathrm{H}$. Carotid gustatory syndrome in a patient with Holmes-Adie syndrome. $\mathcal{f}$ Neurol Neurosurg Psychiatry 1990;53:359.

9 Burns R, Wing L. Adie's syndrome (tonic pupil and reflexia). Sweating disturbances and diarrhoea-a new syndrome? Clin Exp Neurol 1980;17:243.

10 Harriman D, Garland $\mathrm{H}$. The pathology of Adies syndrome. Brain 1968;91:401-18.

11 Smith S. Pupil function tests and disorders. In: Bannister R, Mathias CJ, eds. Autonomic failure, a textbook of clinical disMathias CJ, eds. Autonomic failure, a textbook of clinical dis-
orders of the autonomic system. 3rd ed. Oxford: Oxford Uniorders of the autonomic system.
versity Press, 1992:421-41.

12 Mathias CJ, Bannister R. Investigation of autonomic disorders. In: Bannister R, Mathias CJ, eds. Autonomic failure. A textbook of clinical disorders of the autonomic system. 3rd ed. Oxford: Oxford University Press, 1992:255-90.

13 Fuller R, Choudry N. Increased cough reflex associated with angiotensin converting enzyme inhibitor cough. BMf 1987;295:1025-6.

14 Hope-Ross M, Buchanan T, Archer D, et al. Autonomic function in Holmes-Adie syndrome. Eye 1990;4:607-12.

15 Hersch M, McCleod J, Sullivan C. Abnormal cough reflex in canine acrylamide neuropathy. Ann Neurol 1989;26:73845

16 Vianna L, Gilbey S, Barnes N, et al. Cough threshold to citric acid in diabetic patients with and without autonomic neuropathy. Thorax 1988;43:569-71.

17 Fuller R. Cough. In: Brewis R, Corrin B, Geddes D, et al, eds. Respiratory medicine. 2nd ed. London: Saunders, 1995: $238-42$

18 Ramsey E, Uthman B, Augustinsson L, et al. Vagus nerve stimulation for treatment of partial seizures: 2 . Safety, side effects and tolerability. Epilepsia 1994;35:627-6. 